\title{
Is your antiseptic effective against clinical multidrug- resistant microorganisms? A chlorhexidine digluconate formulation demonstrates efficacy even in lower concentrations
}

\author{
NT Mutters', F Günther, S Kaiser, T Fries, U Frank \\ From 3rd International Conference on Prevention and Infection Control (ICPIC 2015) \\ Geneva, Switzerland. 16-19 June 2015
}

\section{Introduction}

Managing Healthcare-associated Infections (HAI) and multidrug-resistant Microorganisms (MDRO) is a daily challenge in hospitals. Universal decolonization by daily bathing with impregnated cloths can result in a reduction of HAIs.

\section{Objectives}

The objective of this study was to measure the effectiveness of a Chlorhexidine digluconate (CHG) formulation against clinical MDRO.

\section{Methods}

Gram-negatives were classified as extensively drug-resistant (XDR-GN) [1]. Additionally, MRSA and VRE isolates were tested. CHG was tested in concentrations of $20 \mathrm{mg} / \mathrm{ml}$, $10 \mathrm{mg} / \mathrm{ml}$, and $5 \mathrm{mg} / \mathrm{ml}$. Two analyses were performed. (1) A quantitative suspension test according to European Standard EN 12353 [2]. Briefly, bactericidal efficacy was determined without organic load, neutralizations was achieved by Caso-bouillon and LTHTh. (2) MIC testing procedures were based on those outlined in the FDA Tentative Final Monograph. Briefly, a 96 well microtitre plate containing doubling dilutions of $\mathrm{CHG}$ was set up; broth culltures were standardised to $1 \times 10^{\wedge} 8 \mathrm{CFU} / \mathrm{mL}$ and added. MIC was defined as the lowest concentration of CHG at which no bacterial growth was observed.

\section{Results}

The suspension tests showed good susceptibility to CHG of all strains. Reduction rates were $99.9-100 \%$ for all strains even in lower concentrations. At 15 seconds and a CHG concentration of $5 \mathrm{mg} / \mathrm{ml}$ a $99.97 \%$ reduction of XDR P. aeruginosa, a $99.99 \%$ reduction of XRD K. pneumoniae, and a $99.94 \%$ reduction of XDR E. coli could be demonstrated. The MIC analysis showed efficacy ranging 19.53 to $39.06 \mu \mathrm{g} / \mathrm{ml}$ in XDR P. aeruginosa, 4.88 to $39.06 \mu \mathrm{g} / \mathrm{ml}$ in XDR K. pneumoniae, and 4.88 to $9.77 \mu \mathrm{g} / \mathrm{ml}$ in XDR E. coli. MRSA showed very low MICs ranging from $1: 8192$ to $1: 65536$; VRE showed MICs ranging from $1: 512$ to $1: 2048$.

\section{Conclusion}

In both analyses, CHG demonstrated an excellent performance against MDRO. The results of these clinical isolates studies and the concentration achieved on patient's skin demonstrate a very large safety margin when using this formulation. Effective decolonization of patients' skin can play an important role in reducing risk of HAIs.

\section{Disclosure of interest}

None declared.

Published: 16 June 2015

\section{References}

1. Magiorakos, et al: Multidrug-resistant [...] resistance. CMI 2011. 2. European Normative: Chemical disinfectants [...] version EN 12353. 2013.

\section{doi:10.1186/2047-2994-4-S1-P34}

Cite this article as: Mutters et al:: Is your antiseptic effective against clinical multidrug-resistant microorganisms? A chlorhexidine digluconate formulation demonstrates efficacy even in lower concentrations. Antimicrobial Resistance and Infection Control 2015 4(Suppl 1):P34. 